Original Research Article

\title{
Adverse drug reactions due to cancer chemotherapy in a tertiary care hospital in south Karnataka: a prospective observational study
}

\author{
Sowmya M. S. ${ }^{1}$, Basavanna P. L. ${ }^{1}$ *, L. Raghavendra Gupta ${ }^{2}$
}

\begin{abstract}
${ }^{1}$ Department of Clinical
Pharmacology, ${ }^{2}$ Patient safety

Pharmacovigilance Associate, Mysore Medical College and

Research Institute, Mysore,

Karnataka, India
\end{abstract}

Received: 27 September 2019

Revised: 11 November 2019

Accepted: 12 November 2019

*Correspondence to:

Dr. Basavanna P. L.,

Email: drbasavannapl@

gmail.com

Copyright: (C) the author(s), publisher and licensee Medip Academy. This is an openaccess article distributed under the terms of the Creative Commons Attribution NonCommercial License, which permits unrestricted noncommercial use, distribution, and reproduction in any medium, provided the original work is properly cited.

\begin{abstract}
Background: Cancer is a multi-cellular disease which can arise from any cell type and organs. Adverse drug reactions (ADR) are undesirable consequence of cancer chemotherapeutic drugs. A great importance has to be given for their assessment, detection, monitoring, reporting and preventing these ADR for the beneficial effects of the patients. So the present study was undertaken for the purpose of detecting and quantifying those adverse reactions which is of some importance in therapeutic setting.

Methods: A prospective observational study conducted in chemotherapy ward, male and female patients of any age receiving cancer chemotherapy and presenting with ADR's in duration of 3 months.

Results: 160 patients were observed. Out of 160 patients 123 presented with ADR's. Most common ADR's were loss of appetite (67.6), diarrhea (61.8\%), vomiting $(21.5 \%)$, nausea $(17.7 \%)$, anemia $(24.7 \%)$. Cisplatin, paclitaxel, oxaliplatin, doxorubicin, gefitinib are common drugs causing ADR's.

Conclusions: Cancer chemotherapeutic drugs are associated with various adverse reactions. This study shows the importance of active monitoring of these reactions and measures to prevent their effects early in the treatment of cancer.
\end{abstract}

Keywords: ADR, Pharmacovigilance, Cancer chemotherapy

\section{INTRODUCTION}

An adverse drug reaction (ADR) is defined by World Health Organization as "any response to a drug which is noxious, unintended and occurs at doses used in man for prophylaxis, diagnosis or therapy". "Cancer is a multicellular disease which can arise from any cell type and organs. Chemotherapy is one of the approach in the management of cancer. Some of the cancers are proven to be curable now. Though these chemotherapeutic agents are useful in treating cancer, they are commonly associated with many ADRs which impairs the quality of life, decrease the work productivity of patients. These ADRs would affect the patient clinically and economically by increasing hospital visit, hospital admission and prolonging the hospital stay.
The most commonly used chemotherapeutic agents are cisplatin, carboplatin, paclitaxel, oxaliplatin, doxorubicin etc., and they would cause mild ADR like nausea, vomiting, diarrhea to severe ADR like immunosuppression. Sometimes the ADRs are so serious and severe that, cost needed to treat morbidity and mortality due to it, is more than the cost needed to treat the actual condition of interest. ${ }^{2}$ With the introduction of pharmacovigilance in the recent times, more ADRs are reported and documented in various parts of the world which would actually help in proper analysis of the severity and prevention of these ADR's and improve the quality of life of the patients. The outcome would help to create awareness among the healthcare providers and to prevent further ADR in the subsequent chemotherapy cycles. $^{3}$ 
There is very less data regarding the safety profile of cancer chemotherapy in South India. So, the objective of the present study was to evaluate the pattern of ADRs occurring in cancer patients treated with chemotherapy in a tertiary care hospital in south India.

\section{METHODS}

\section{Study design}

The study was a hospital based prospective observational study conducted from May to July 2019 in patients who received chemotherapy in Oncology ward of a tertiary care hospital, K R Hospital, Mysore Medical College and Research Institute, Mysore after taking approval from institutional ethical committee.

\section{Inclusion and exclusion criteria}

Among the patients receiving chemotherapy, those developed at least one ADR were included in the study and those who did not show any ADR were excluded from the study.

\section{Study tools}

In accordance to the ADR, ADR reporting form of Central Drugs Standard Control Organisation, Government of India, were used to collect the data regarding the details of drugs received during chemotherapy cycle and also pre-existing medical condition if any. All the suspected ADR were reported to ADR monitoring centre and also in Vigiflow to National coordination Centre. To assess the causality, Naranjo Causality Assessment Scale was used. ${ }^{4}$

\section{Study analysis}

After collecting data it was entered in MS Excel sheet. Later datasheet was generated and copied to SPSS (version 21.0). Then the analysis was done in SPSS (21.0).

\section{RESULTS}

In our study 160 patients were observed with chemotherapy. Out of which only 123 patients presented with ADR's. Out of 160 patients females were 91 $(57.6 \%)$ and males were $65(42.4 \%)$ patients. Their demographic and socioeconomic status is shown in Table 1. Most common age group was found to be between 4060 years. Socio-economic status was assessed using modified Kuppuswamy scale. ${ }^{5}$

It was found that $9.7 \%$ of the study population was from upper socio economic status and $47.7 \%$ was from lower middle class family. Among the ADR's noted, most common ADR was loss of appetite (67.6), diarrhea $(61.8 \%)$ vomiting $(21.5 \%)$, anemia (24.7\%), nausea $(17.7 \%)$. Cisplatin, paclitaxel, oxaliplatin, doxorubicin are common drugs causing ADR's.

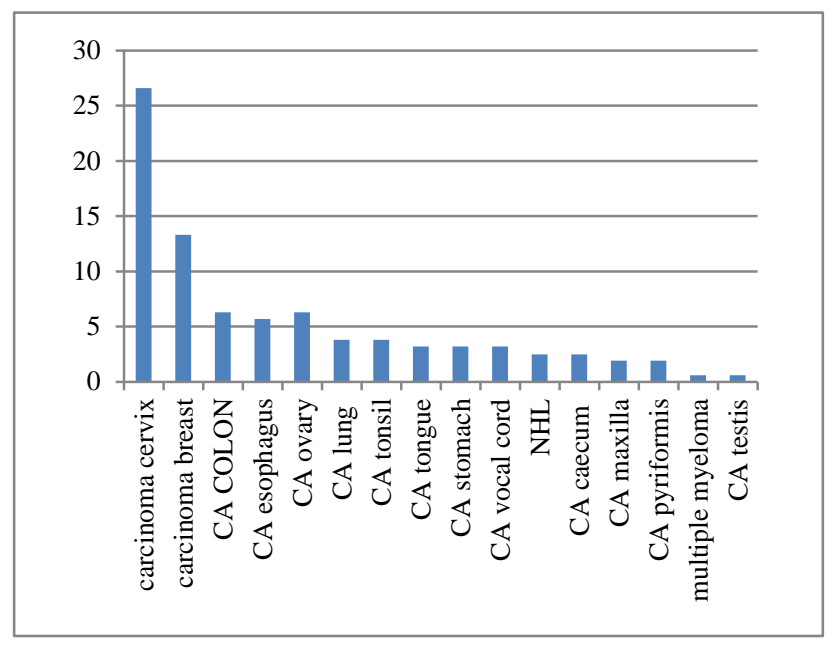

Figure 1: Categories of cancer patients observed.

Table 1: Demographic characteristics $(n=123)$.

\begin{tabular}{|llll|}
\hline \multirow{5}{*}{ Gender } & & Number & $\%$ \\
& Male & 49 & 39.8 \\
\cline { 2 - 4 } & Female & 72 & 58.5 \\
\hline \multirow{5}{*}{ Age (in years) } & Upto 20 & 2 & 1.6 \\
\hline & $21-30$ & 12 & 9.7 \\
\cline { 2 - 4 } & $31-40$ & 21 & 17.07 \\
\hline \multirow{3}{*}{ Socioeconomic status } & $41-50$ & 35 & 28.45 \\
\cline { 2 - 4 } & $51-60$ & 36 & 29.26 \\
\cline { 2 - 4 } & $>60$ & 17 & 13.82 \\
\hline \multirow{5}{*}{ BMI } & High & 12 & 9.7 \\
\cline { 2 - 4 } & Average & 53 & 43 \\
\cline { 2 - 4 } & Low & 58 & 47.7 \\
\cline { 2 - 4 } & Underweight (below $\left.18.5 \mathrm{~kg} / \mathrm{m}^{2}\right)$ & 36 & 29.2 \\
\cline { 2 - 4 } & Normal (18.5-24.9) & 62 & 17.8 \\
\cline { 2 - 4 } & Overweight (25.5-29.5) & 22 & 2.4 \\
\cline { 2 - 4 } & Obese (30 and above) & 03 & \\
\hline
\end{tabular}




\section{Causality and severity assessment}

In this study it showed that $23.4 \%$ was probable, $68.2 \%$ was possible and $8.4 \%$ was definite reactions according to Naranjo causality assessment scale.

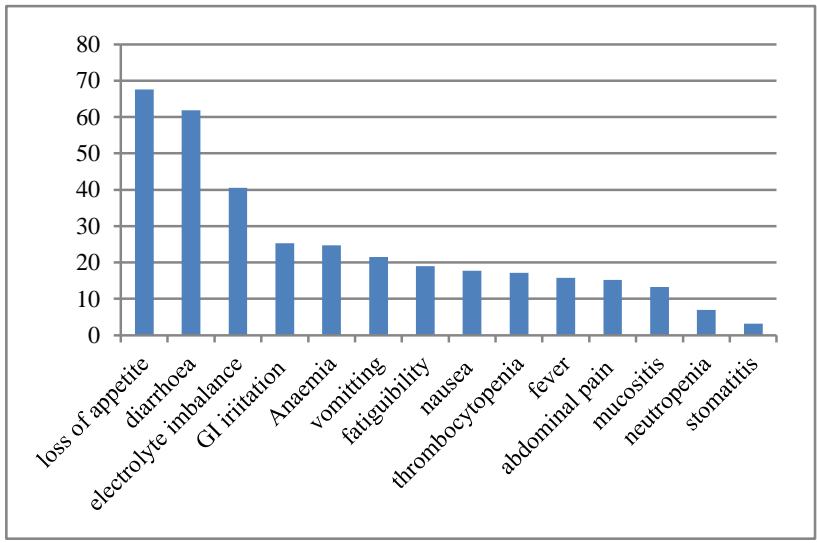

Figure 2: Adverse drug reactions observed among cancer chemotherapy patients.

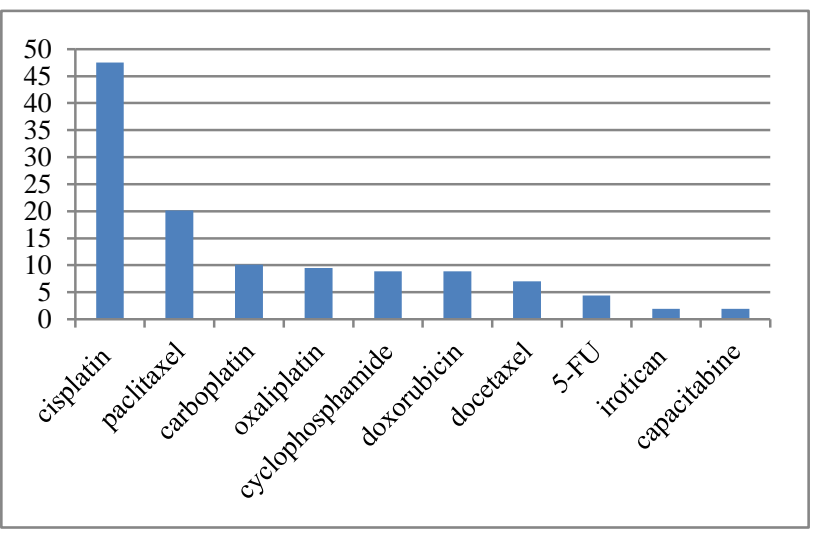

Figure 3: Drugs responsible for adverse drug reactions.

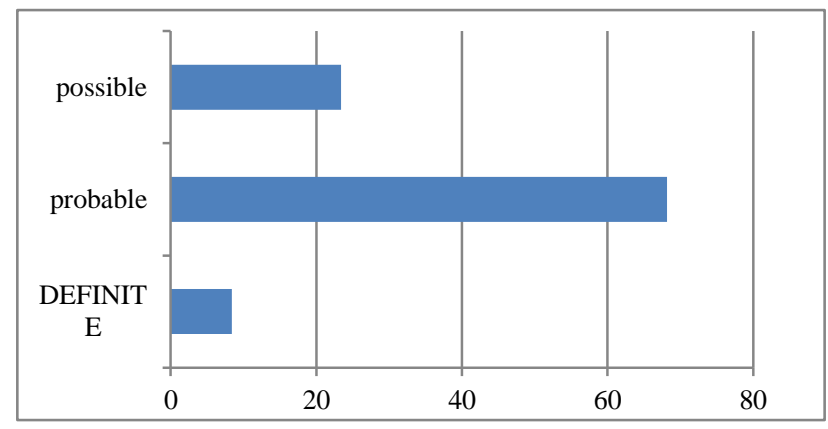

Figure 4: Naranjo causality assessment scale.

\section{DISCUSSION}

In our study it is found that the incidence of ADR was found to be higher in female patients and also the increased incidence is seen in mean age of $45 \pm 10$ years similar to study conducted by Podder et al. ${ }^{6}$ The incidence of ADR was more common in elderly patients which could be due to the decreased organ function and decreased metabolizing activity and decreased excretion of the drugs leading to their accumulation in the body and leading to this scenario. ${ }^{7}$ And the majority of the patients admitted in hospital for cancer chemotherapy were upper middle class and lower economic class population according to the socio economic status of the patients.

Cisplatin, paclitaxel, carboplatin, oxaliplatin, cyclophosphamide regimens are more commonly associated with ADR which is comparable with other study reports. ${ }^{8}$ The most common system involved in ADR was gastrointestinal tract with the symptoms like loss of appetite, vomiting and diarrhea which is similar to study. ${ }^{9}$ In our study nausea and vomiting was less compared to other ADR's and this was because of the premedication given to the patients i.e., antiemetics like ondensatron, ranitidine, pantoprazole, dexamethasone etc.

Anaemia was found in $24.7 \%$ of the patients which could be due to chemotherapy induced myelosuppression which normally occurs 2-3 weeks after starting chemotherapy which could be managed by blood transfusion and erythropoietin. ${ }^{10}$ Neutropenia was seen in $7 \%$ of the patients which could be due to chemotherapy which can also damage rapidly dividing cells of bone marrow resulting in myelosuppression thus affecting white blood cells, platelets and red blood cells. ${ }^{10}$ Thrombocytopenia was found to be $17.2 \%$ in the patients receiving cancer chemotherapy which was grade I and grade II. Grade III and Grade IV thrombocytopenia might lead to complications, delay in the treatment, poor outcome and bad prognosis of the patient. ${ }^{11}$

Data obtained from Naranjo causality assessment scale showed $23.4 \%$ of the ADR fell into category of possible, $68.2 \%$ of the ADR into probable and $8.4 \%$ into definite category. The severity assessment was done using Hartwig et al severity scale and it was found that $77 \%$ of the ADR's were mild, $19.8 \%$ was found to be moderate and $3.2 \%$ was found to be severe. Mild reactions did not require any change of drugs nor extended hospital stay, were patients with moderate reactions substituted with alternative drugs and treatment for the reactions. Severe ADR increased the hospital stay, increased financial expenditure.

\section{CONCLUSION}

Cancer was a leading cause of death worldwide but with the recent advances in cancer chemotherapy some of the cancers are proven to be cured. But these cancer chemotherapy are associated with various ADRs. This study highlights the common ADR's associated with the cancer chemotherapy drugs and gives an insight of causality and severity of ADRs associated with chemotherapy and this is to create awareness among the healthcare providers which would help to prevent further occurrence of similar reactions in the same patient. The 
main intension behind this has led to early detection of common ADR and to contribute towards achieving goal of pharmacovigilance in the country.

Funding: No funding sources

Conflict of interest: None declared

Ethical approval: The study was approved by the Institutional Ethics Committee

\section{REFERENCES}

1. Tripathi KD. Essentials of Medical Pharmacology. 8th ed. New Delhi, India: Jaypee Brothers Medical Publishers; 2019.

2. Smith DL. The effect of patient non- compliance on health care costs. Med Interface. 1993;6:74-84.

3. Wahlang JB, Laishram PD, Brahma DK, Sarkar C, Lahon J, Nongkynrih BS. Adverse drug reactions due to cancer chemotherapy in a tertiary care teaching hospital. Ther Adv Drug Saf. 2017;8(2):61-6.

4. Zaki SA. Adverse drug reaction and causality assessment scales. Lung India. 2011;28:152-3.

5. Kumar N, Gupta N, Kishore J. Kuppuswamy's socioeconomic scale: Updating income ranges for the year 2012. Indian J Public Health 2012;56:103-4.

6. Poddar S, Sultana R, Sultana R, Akbor MM, Azad MAK, Hasnat A. Pattern of adverse drug reactions due to cancer chemotherapy in tertiary care teaching hospital in Bangladesh. Dhaka Univ J Pharm Sci. 2009;8:11-6.
7. Bates DW, Leape L. Adverse drug reaction. Morreli's Clinical Pharmacology. 4th edn. Boston, USA: McGraw-Hill; 2000: 15.

8. Sharma A, Kumari K, Manohar H, Bairy K, Thomas, J. Pattern of adverse drug reactions due to cancer chemotherapy in a tertiary care hospital in South India. Perspect Clin Res. 2015;6:109-15.

9. Guo H, Ren R, Zhang D, Ji M. Monitoring report on 341 cases of adverse reactions caused by antitumor drugs. Afr J Microbiol Res. 2012;6:3774-7.

10. Prasad A, Datta PP, Bhattacharya J, Pattanayak C, Chauhan AS, Panda P. Pattern of adverse drug reactions due to cancer chemotherapy in a tertiary care teaching hospital in eastern India. J Pharmacovigilance. 2013;1(2):1-4.

11. Schiffer CA, Anderson KC, Bennett CL, Bernstein S, Elting LS, Goldsmith M, et al. Platelet transfusion for patients with cancer: clinical practice guidelines of the American Society of Clinical Oncology. J Clin Oncol. 2001;19(5):1519-38.

Cite this article as: Sowmya MS, Basavanna PL, Gupta LR. Adverse drug reactions due to cancer chemotherapy in a tertiary care hospital in south Karnataka: a prospective observational study. Int J Basic Clin Pharmacol 2019;8:2635-8. 